\title{
Study on Teacher-Student Interaction in the Ideological and Political Theory Teaching Based on SPOC Model
}

\author{
Wen-Ying $\mathrm{LU}^{1, \mathrm{a}}$, Ai JIAN ${ }^{2, \mathrm{~b}, *}$ \\ ${ }^{1}$ General Education Center of Xi'an Peihua University , Xi'an City , China, 710125 \\ ${ }^{2}$ General Education Center of Xi'an Peihua University , Xi'an City , China, 710125 \\ a275383882@qq.com, ${ }^{\mathrm{a}}$ 459820679@qq.com \\ * Ai Jian
}

Keywords: SPOC mode, teacher-student interaction, synergetic mechanism

\begin{abstract}
SPOC teaching mode, in order to improve the effectiveness of teacher-student interaction and the teaching efficiency of ideological and political theory courses and gradually establish a new pattern of teacher-student interaction featuring "harmony, democracy, integration and development”. In the face of the new generation of Internet-post-95s college students, the SPOC teaching mode is used in the ideological and political theory teaching. An analysis of the teaching links and processes founds that teacher-student interaction has a direct influence on the ideological and political teaching under this mode. However, accustomed to the traditional practice, there exists dilemma where the teacher-student interaction is one-way, under control and neglect of invisible classroom and insufficient of emotional communication. Based on the analysis of problem causes, the open, competition and cooperation and self-organized coordination mechanism is introduced.

In nowadays when the modern information technology has a huge impact on all walks of life, the education sector has also suffered a lot. For the new generation of the Internet-post-95s college students, it is necessary to introduce the information technology and the Internet application. If a new trial is made in ideological and political theory teaching in combination with the internet platform, it will undoubtedly have important theoretical and practical significance to the enhanced efficiency of teaching. The SPOC model precisely works well by taking advantage of the quality comprehensive resources provided by famous universities on the MOOCs platform.

Traditionally, teaching internalization and transference is limited within the classroom while on this platform knowledge impartation goes beyond the classroom. Students are thus able to achieve personalized learning; a new integrated teaching mode that pays more attention to the teacher-student interaction outside of the classroom is taking shape.
\end{abstract}

\section{Teacher-Student Interaction to be Much Highlighted in the Ideological and Political Theory Teaching under SPOC Mode}

In the ideological and political theory teaching, the use of SPOC model enables each link of teaching to depend much more on the effective teacher-student interaction, otherwise the teaching and learning under this mode will degrade to formality.

First of all, teachers' and students' preparation and study before class, which involves students grouping, group member consent, material provision before class and students' smooth use of this platform, to teachers' urging and reminding students to watch course video and complete learning task list, then to accumulation and evaluation of learning status record and process evaluation material, etc. The smooth implementation of the links cannot be realized without constant active, meticulous, patient interaction and exchange between teachers and students through the SPOC platform, WeChat, SMS, QQ group, phone, mail, etc. By doing these, can it truly enable students to successfully complete learning before class, fully understand the basics of each unit of the ideological and political theory course and lay the foundation for the curricular practice and demonstration.

Second, teachers guide students to complete knowledge internalization, practice and transference. This process begins with displaying and sharing of pre-class learning results, to each group's raising 
puzzles and problems, then to other group member's answering or proposing different ideas and to teachers and students' mutual efforts to solve most of most puzzles and problems and ends in teachers' organizing students to complete related practices and reviews.

In short, in the ideological and political theory teaching under the SPOC model, the chances for student-student, teacher-student interaction and exchange have multiplied. Other teaching modes are unparallel in terms of interaction quantity, quality or from.

\section{Problems in the Ideological and Political Theory Teaching under SPOC Mode}

Compared to other modes of teaching, one of the most prominent advantages for the SPOC teaching mode is the enhanced teacher-student interaction. The effective, full and better competence for the ideological and political theory teaching under the SPOC model requires a new teacher-student relationship featuring democracy, equality, openness and freedom through positive, active and frequent interactions between teacher and students and among students [1]. However, constrained by teachers and students' position, the organizational structure, teaching philosophy and management mechanism and other factors, problems are in fact found from teacher-student interaction in the ideological and political theory teaching practice under SPOC model.

\section{Teacher-Student Interaction is One-Way Instead of Two-Way, under Control Instead of under Democracy and Equality}

Based on the ideological and political teaching practice under the SPOC model, it's found through actual observation, understanding and visits that the status of teachers and students that formed in the traditional teaching habitually continued to play a role in the ideological and political teaching practice under the SPOC model. Specific things are as follows: on one hand, the teacher-student interaction is one way instead of two-way. In the teaching links, the teacher simply gives instruction, and students rarely ask questions, give feedback or do interaction with the teacher. There are still some students staying unchanged even if the teacher who uses the SPOC mode practice seems to have racked his brain to mobilize students; on the other hand, in the instruction-dominated traditional teaching whose organizational structure and management mechanisms emphasize to which extent the teacher must play a role, this will bring about such dominating and being dominated relationship between teachers and students; teachers' expertise advantage developed trough years' delving into this field will worsen such inequality in resource possession and knowledge mastery between students and teachers; third, in the e ideological and political theory teaching practice under the SPOC mode, the teacher will consciously or unconsciously follow the tradition and plays a control role in interaction with students, and students will also consciously become obedient accordingly.

\section{Visible Classroom-Oriented and Invisible Classroom-Ignored in Teacher-Student Interaction}

In the ideological and political theory teaching under the SPOC mode, it must be that students complete instructional videos, teaching materials and tasks before class on the basis of pre-class teacher-student interaction, while the teacher prepares for the class by understanding students' pre-class learning status so as to help students to complete knowledge internalization and practice; that's a kind of pre-class learning through invisible classroom. In this way, the teacher design class activities in combination with the students' learning status and give full play to the role of the teacher-student interaction in the visible classroom, so as to achieve the objective of knowledge internalization, operation, transference and practice. In contrast, under the influence of traditional teaching structure and teaching philosophy, the students and teachers care more about lessons and pay little attention to pre-class learning, arguing that the teacher will after all give explanation and instruction. This will result in no actual invisible classroom even under the SPOC mode. The teacher instead purely gives orders, assigns tasks, lacking teacher-student interaction. This sets up a barrier for knowledge internalization, operation, transference and practice and devalues the effectiveness of 
visible classroom. That's also one main reason why the teacher thinks the teaching result is not ideal in the ideological and political theory teaching under the SPOC mode.

\section{Teacher-Student Interaction is Knowledge Impartation-Based and Lack of Emotional Communication}

Teacher-student interaction includes such two-way feedback process as thoughts and feeling exchange and information impartation. However, the traditional teaching management system uses evaluation a tool and focus only on whether students have learnt knowledge and skills or not, but ignores the emotional aspects of teacher-student interaction. Therefore, in the ideological and political theory teaching practice under the SPOC mode, student-teacher interaction mostly focuses on cognitive activities and tends to information transference; what they have interact are subject knowledge-based and features simplification and rationalization [2]. There lacks emotional interaction and even thought and deep spiritual exchange in teacher's question and students' responses. Such interaction serves no more than as a tool and it is impossible to achieve the desired effect of the ideological and political theory course - students love it from inner heart and will benefit and keep it in mind lifetime. What's more, the teacher-student relationship in universities is relatively loose: they rarely see each other after class. This will naturally makes it strange between teachers and students, and there lacks of emotional communication.

\section{Strategies to Improve the Teacher-Student Interaction Effect in the Ideological and Political Theory Teaching under SPOC Mode}

To overcome students and teachers' limitation in their interaction and problems in the practical teaching process, the introduction of synergistic mechanism is an effective strategy. Synergistic mechanism as a power mechanism has openness, competition and collaboration, self-organization and other elements. Each element has its own irreplaceable role and function. The use of synergistic mechanism can break through the passive pattern predominated by teachers while students are subordinated. It can also improve the efficiency of interaction. A new student-teacher interaction pattern featuring harmony, democracy, integration and development will take form in the way of students' self-organization.

\section{Introduction of Synergetic Mechanism Element One: Openness}

The reason for introducing synergetic mechanism openness in the ideological and political theory teaching under the SPOC mode is that openness allows the material, energy and information exchange between the system and external and among sub-systems within the system, so that it can provide inexhaustible nourishment for inter-system and -subsystem development. [3] This kind of openness takes whether it is conducive to student learning as standard rather than openness without principal and rules. Whatever is conducive to student learning can be admissible and whatever is not will be refused as much as possible. In other words, narrowness should be avoided due to the subject's insufficient participation; lack of tolerance should be avoided either due to insufficient openness, so that students can express different or deeper opinions about the ideological and political theory courses. On the other hand, excessive openness should also be avoided; otherwise it may cause waste of time or distraction of attention. The purpose of openness is to emancipate students' mind with regard to interaction contents and try not to constraint their active thinking, while to avoid the reference to irrelevant topics. Students should pay particular attention to the collection of interaction results by students, arrange them orderly and gradually push forward the progressive trend. This is conducive to sustained and sound development of teacher-student interaction in the ideological and political theory teaching.

\section{Introduction of Synergetic Mechanism Element Two: Competition and Cooperation}

This paper introduces competition and cooperation under the synergetic mechanism into the ideological and political theory teaching under SPOC mode. Cooperation can foster strengthen and 
avoid weaknesses, while competition can seek maximum development, i.e. competition and cooperation are mutually supportive and interdependent. The most active impetus during the system evolution is competition and cooperation, which can make the whole system in a state of positive active.

In the ideological and political theory teaching under the SPOC model, students are grouped to complete pre-class learning. This lays a foundation for taking competiveness and coordination strategy. On the basis of understanding of the relationship between students, the groups or teams formed for some reason are divided into groups. Under the supervision and guidance of teachers, group member collaborate with each other and different groups conduct competition. At the same time, incentives mechanism is supplemented such as bonus point, present award, etc.

In the joint action of the various groups, sparks of wisdom easily come out from the interaction and collision. During the changes brought by the teacher-student interaction, the teacher's constant awareness of instruction will gradually bring progress to students and deepen the interacted content; effective internalization and transference of ideological and political theory knowledge will then achieved to students. Therefore, competition and cooperation is an effective strategy of teacher-student interaction.

\section{Introduction of Synergetic Mechanism Element Three: Self-Organization}

Self-organization, a high-level stage of the teacher-student interaction, takes its form after repeated and effective use of openness, competiveness and synergism mechanism. The reasonable and effective use of teacher-student interaction in the synergetic mechanism factor will finally give birth to self-organized operation mode. During constant interaction in the classroom, students will really feel the benefits interaction gradually brought: one of them is to make collective atmosphere harmonious and active and improve the initiative and cooperation awareness of the individual; the second benefit is to enhance the development of individual thinking during collision with different ideas and improve the individuals' practical ability; the third benefit is to enhance the flexibility of teaching, and give rise to the emergence of new ideas, new methods, new results; the forth benefit is to better inspire students to learn well and enable them to develop from resistance to passive acceptance then to self-organization. Teachers do not have to worry about this anymore; students will not only actively participate in interaction, but will take the initiative to accept and consciously create interactive atmosphere. The interaction effect satisfactory to both teachers and students will be achieved. Once the self-organization collaborative dynamic mechanism takes shape, the leading force in teaching different groups can come together through various elements within the competiveness system and the vigorous situation will not be undermined in spite of few disharmonious factors.

\section{Summary}

In summary, the teacher-student interaction is communication and exchange conducted by students and teachers for the purpose of completing ideological and political theory course learning objectives and also one means for smooth teaching and achieving results. The completion of teaching on the one hand requires the learner must have appropriate abstract thinking ability and mental level; on the other hand requires the instruction from an experienced "precedent learner". Such instruction can save time and also effectively solve the problems encountered by learners. Scientific teaching must have sufficient and effective teacher-student interaction. If the teacher-student interaction is not enough or cannot fully play a role, the teaching of ideological and political theory course based on SPOC mode will not actually achieve various values (such as knowledge, ability, character, etc. ). Therefore, only equality between teachers and students can render teacher-student interaction, and only interaction can make it possible to realize teaching value and to implement the overall development purpose for students. Aiming at the existing problems, this paper introduces openness, competition and self- organization and other elements of the synergic mechanism, in order to effectively improve the teacher-student interaction quality. Furthermore, the implementation of 
SPOC teaching mode will help enhance ideological and political quality of teaching and improve students' learning efficiency so that they can embark on the way to success and better become qualified innovative and complex talents required for socialist construction, and teachers can grow into high-efficient educators keeping up with the pace.

\section{Acknowledgement}

This research was the research result of Shaanxi Provincial Institute of Higher Education's project themed "research on teachers' MOOC teaching competency constituency and development in Xi'an private colleges and universities" (project t number 15GJ032) and the research result of Xi' an Peihua University's education reform project themed "research on curriculum construction and application in teaching practice based on SPOC model” (project number PHY1614).

\section{References}

[1] Wang Youhua, Study on Interactive Teaching Strategy under Flipped Classroom Teaching Mode - A Case Study of College English Course [J]. Data of Culture and Education, 2015,11: 179-181.

[2] Xiao Xiangping, Xu Xiaoxia, Construction and Practice of “Inter-subjectivity” Teacher-Student Interaction Mode [J] Chinese University Teaching, 2015,07: 66-69.

[3] Li Ying, Zhang Weiping, Teacher-Student Interaction Cooperation Mechanism: Elements Deconstruction and Strategy Discussion [J] Education Exploration, 2012, 12: 14-16.

[4] Xiong Kuanghan, Discussion on Teacher-Student Interaction and Realization of Teaching Value [J] Chinese University Teaching, 2009, 04: 21-23.

[5] Ye Donglian, Wan Kun [J]. Study on Teacher- Student Interaction Effect Based on Participatory Teaching Mode in Flipped Classroom [J]. Modern Educational Technology, 2014, 12: 77-83.

[6] Du Yongqiang, Chen Bohua, Teacher-Student Interaction Behavioral Research [J] Educational Science Research, 2014 (10): 66-70. 